\title{
Oxygen Supplies in Disaster Management
}

\author{
Thomas C Blakeman MSc RRT and Richard D Branson MSc RRT FAARC
}

\author{
Introduction \\ Hospitals \\ Planning \\ Disaster Assistance \\ Vulnerabilities \\ The Community \\ Vulnerabilities \\ Effect on Hospitals \\ Home Oxygen Patients Disaster Planning \\ Alternate Care Facilities \\ Oxygen Sources \\ Concentrators \\ Cylinders \\ Liquid Oxygen \\ Multi-Patient Manifold Systems \\ Summary
}

\begin{abstract}
Mass casualty events and disasters, both natural and human-generated, occur frequently around the world and can generate scores of injured or ill victims in need of resources. Of the available medical supplies, oxygen remains the critical consumable resource in disaster management. Strategic management of oxygen supplies in disaster scenarios remains a priority. Hospitals have large supplies of liquid oxygen and a supply of compressed gas oxygen cylinders that allow several days of reserve, but a large influx of patients from a disaster can strain these resources. Most backup liquid oxygen supplies are attached to the main liquid system and supply line. In the event of damage to the main system, the reserve supply is rendered useless. The Strategic National Stockpile supplies medications, medical supplies, and equipment to disaster areas, but it does not supply oxygen. Contracted vendors can deliver oxygen to alternate care facilities in disaster areas, in the form of concentrators, compressed gas cylinders, and liquid oxygen. Planning for oxygen needs following a disaster still presents a substantial challenge, but alternate care facilities have proven to be valuable in relieving pressure from the mass influx of patients into hospitals, especially for those on home oxygen who require only an electrical source to power their oxygen concentrator. Key words: oxygen; disaster; compressed gas; emergency preparedness; liquid oxygen; oxygen concentrators. [Respir Care 2013;58(1):173-182. (C) 2013 Daedalus Enterprises]
\end{abstract}

The authors are affiliated with the Division of Trauma and Critical Care, Department of Surgery, University of Cincinnati, Cincinnati, Ohio.

\footnotetext{
Mr Blakeman presented a version of this paper at the 50th RESPIRATORY CARE Journal Conference, “Oxygen,” held April 13-14, 2012, in San Francisco, California.
}

\begin{abstract}
disclosed relationships with Ikaria, General Electric, Covidien, Hamilton Medical, and Breathe Technologies

Correspondence: Thomas C Blakeman MSc RRT, Division of Trauma and Critical Care, Department of Surgery, University of Cincinnati, 231 Albert Sabin Way, Cincinnati OH 45267-0558. E-mail: Thomas. Blakeman@uc.edu.
\end{abstract}

DOI: $10.4187 /$ respcare. 02088 


\section{Oxygen Supplies in Disaster Management}

\section{Introduction}

Mass casualty events and disasters, both natural and human-generated, occur frequently around the world. ${ }^{1}$ Military conflicts, terrorist activities, epidemic and pandemic disease, floods, earthquakes, hurricanes/typhoons, and tsunamis have the potential to destroy infrastructure and strain resources while generating scores of injured or ill victims in need of these resources. The World Health Organization considers a mass casualty an event that produces enough casualties to overwhelm a community's public health and medical services, and classifies a disaster as an event that produces $\geq 10$ deaths or leaves $\geq 100$ people homeless, displaced, or injured. ${ }^{2}$ In the United States, the Department of Homeland Security is charged with coordinating disaster preparedness, response, and recovery through several of its departments, with the majority of the responsibilities falling under the Federal Emergency Management Agency (FEMA) umbrella. ${ }^{3}$ In response to the call for developing comprehensive disaster management, more specifically the care of large numbers of critically ill victims, in 2007 the Task Force for Mass Critical Care examined the current response capabilities. ${ }^{4}$ The task force determined that most countries do not have the space, staffing, and medical equipment and supplies necessary to care for large numbers of victims.

Of the available medical supplies, oxygen remains the critical consumable resource in disaster management. The supply of oxygen, as well as the distribution network, is limited, confounding the problem of having oxygen available where it is needed. Hospitals have large tanks of liquid oxygen (LOX) on site, but in the event this system is destroyed, oxygen by other means, such as cylinders, must be used. Oxygen cylinders are cumbersome, dangerous if mishandled, are often in limited supply, and are currently not included in the Strategic National Stockpile (SNS). ${ }^{5}$ Strategic management of oxygen supplies in disaster scenarios remains a priority. The purpose of this paper is to review the options for backup oxygen supplies and the anticipated oxygen uses in both the hospital and acute care settings, as well as alternate care settings in mass casualty and disaster management.

\section{Hospitals}

Hospitals typically rely on large LOX supplies as their primary oxygen source. One liter of LOX provides approximately $860 \mathrm{~L}$ of gaseous oxygen, making this the most efficient system for oxygen storage and transportation. Alternate sources for oxygen in the hospital setting consist of compressed gas cylinders, usually of the $\mathrm{E}$ and $\mathrm{H}$ sizes. E cylinders are the smaller of the 2, contain approximately $679 \mathrm{~L}$ of oxygen, and, due to their relatively low volume of gas, are typically used for transport of

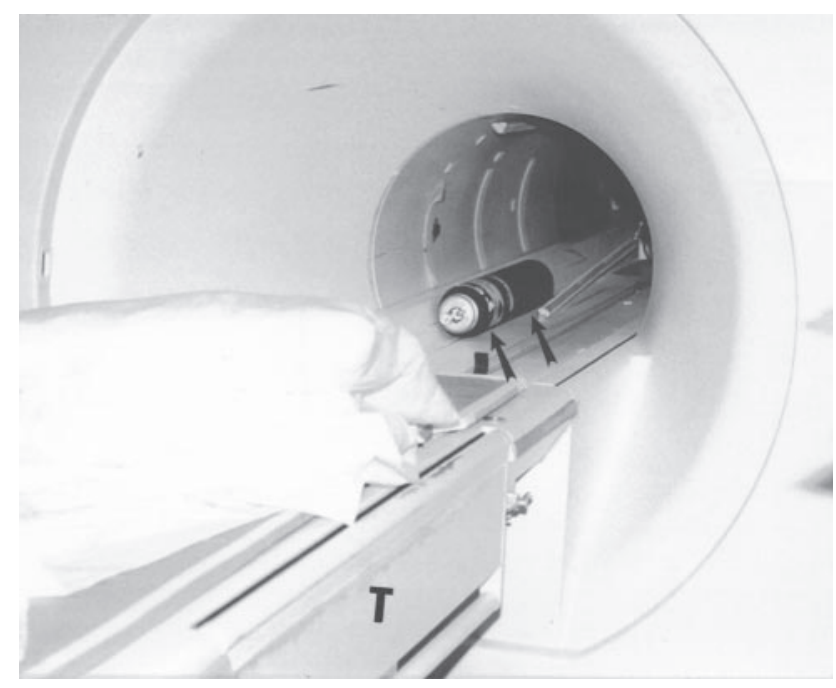

Fig. 1. Oxygen cylinder stuck in magnetic resonance imager (MRI) magnet. (From Reference 6, with permission.)

ventilated and non-ventilated patients and for very short periods of disruption of the main LOX system. H cylinders are much larger and heavier, contain approximately 6,900 L of gas, require a wheeled cart for moving, and are used as the main backup for the LOX system in case of longer periods of disruption. In addition to the cost and storage space required for large reserves of compressed oxygen cylinders, there is also a safety concern. Oxygen cylinders are filled to pressures of 2,000-2,200 psi, whereas the inner pressure of the LOX storage container is approximately 130 psi. Mishandling of oxygen cylinders can result in the cylinder becoming a powerful projectile capable of endangering human life (Fig. 1). ${ }^{6}$ In November 2011 a patient was injured after an oxygen cylinder exploded in the ICU at Bath's Royal United Hospital in the United Kingdom, due to unknown causes. ${ }^{7}$ Although these incidents are rare, the potential for harm is always present, making safe handling and storage of oxygen cylinders both a priority and a problem during a disaster.

Another important consideration in planning for a disaster is the surge of patients coming to the hospital seeking treatment. Even if the hospital is not directly affected, large numbers of patients can easily overwhelm the facility's resources. Healthcare budgetary constraints have forced most hospitals to down-size both the number of beds and the number of staff available. In 2007, $65 \%$ of urban hospitals and $47 \%$ of all hospitals stated their emergency departments were either at or over capacity, and $56 \%$ of urban hospitals reported having to divert patients at some time during that year. Due to down-sizing and continually increasing demand, staffing levels and physical space are already strained and may be woefully inadequate in the event of a major catastrophe. During the surge of patients following a disaster, patients may need to 
be placed in areas not normally used for patient care, such as older parts of the building that previously were used for patient care but have been converted into clinic or outpatient areas or are vacant. If these areas have oxygen that is piped in from the main LOX system, devices such as ventilators that require a 50 psi gas source can be used, further expanding the care capabilities of the facility.

Unfortunately, attaching many ventilators to the oxygen system in the older parts of the building may present another problem: depressurization. The average age of United States hospitals is 27 years, ${ }^{8}$ but many larger urban hospitals are much older. The authors' facility, UC Health University Hospital, was opened in 1823 , and several of the original buildings are still in use. Older hospital buildings that have piped 50 psi oxygen were retrofitted decades ago and were not subject to the building codes in existence today, nor were they designed to supply gas to the oxygen hungry devices currently in use. The older pipes carrying the oxygen are generally much smaller and therefore may not be as able to maintain pressure in cases of high demand. Placing several patients with high oxygen requirements, especially those receiving mechanical ventilation, in these areas may produce pressure drops that render these devices inoperable. Performing appropriate triage and establishing a mix of low and high oxygen demand patients in these areas, along with line pressure monitoring, may prevent depressurization of the system and resulting device failure affecting the most critically ill patients.

\section{Planning}

Planning for a disaster in the hospital environment requires a coordinated effort from many different groups. Planning for oxygen needs and the "what ifs" that may occur during a disaster directly affecting a hospital requires the same coordinated effort. The department that is responsible for the LOX system, usually maintenance, as well as the caregivers applying oxygen to those in need, must have a comprehensive plan that addresses the many issues that could arise. Questions such as, What if we cannot get LOX deliveries? How long will our current LOX supply last? What if the LOX system is damaged? How much gaseous oxygen in cylinders do we have available? What size cylinders do we have, and how will they be distributed? What do we do when there are more patients than oxygen outlets? and What is the back-fill plan? are among the important questions that must be addressed during planning for a disaster. Clearly all of the questions must be answered according to the hospital's current oxygen systems, the size of the facility, the type and magnitude of the disaster, the direct effect on the hospital structure and systems, and the surge size of people seeking treatment.

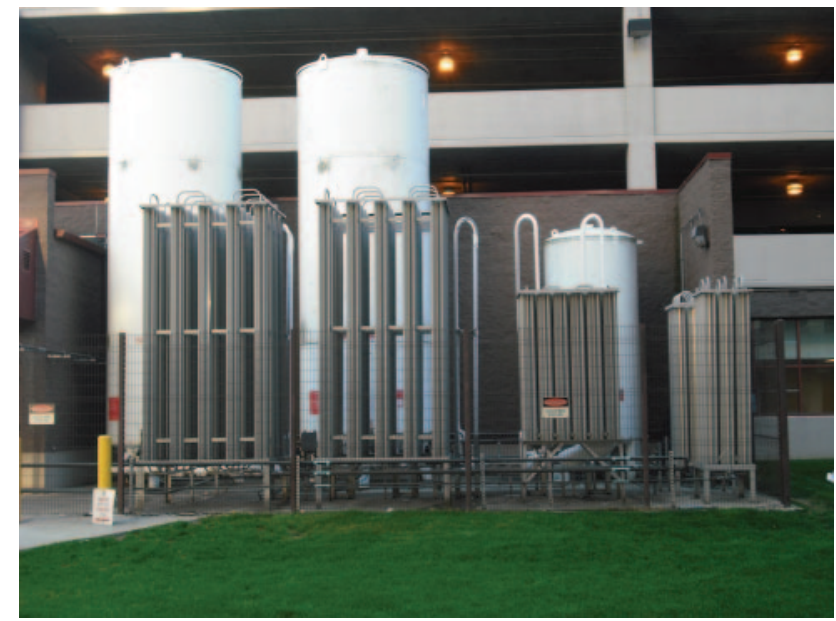

Fig. 2. University Hospital liquid oxygen system.

\section{Disaster Assistance}

When a disaster or mass casualty event occurs, the belief from the public is that the federal government will help provide assistance to the affected areas if the state and local government's disaster capabilities are overwhelmed. FEMA and the Centers for Disease Control and Prevention are 2 federal agencies that provide assistance and guidelines for planning for a disaster. Neither of these agencies have a plan for management of oxygen supplies, in or out of the hospital setting. FEMA's main responsibility is to coordinate disaster recovery, though it usually requires a few days to organize the effort. The Centers for Disease Control and Prevention maintains the SNS in areas around the United States, and is designed to respond more quickly. ${ }^{9}$ The SNS can send their "12-hour push pack" of medications, medical supplies, and equipment to disaster areas within 12 hours of notification of need, but it does not contain oxygen. The SNS does not stockpile oxygen, but instead contracts with private vendors to deliver oxygen when needed. Vendors also have contracts with others who will be requiring oxygen deliveries during this time, which may hamper their ability to meet SNS needs quickly. For these reasons, hospitals must have an adequate backup plan.

Since the SNS does not have the ability to deliver stockpiled oxygen to a hospital following a disaster, what are the other options for the facility? First, those in charge of the LOX must know the storage capacity of the system and the daily usage. Our facility has 693 licensed beds: 130 medical, surgical ICU, burn, and step-down beds; 95 neonatal level I and II beds; 57 level III obstetrics beds; and the remaining are general medical/surgical ward beds. The facility has a large LOX system (Fig. 2) composed of 2 main holding tanks that contain 5,180 and 4,970 gallons (33,000,000 gaseous L), and a reserve tank that contains 


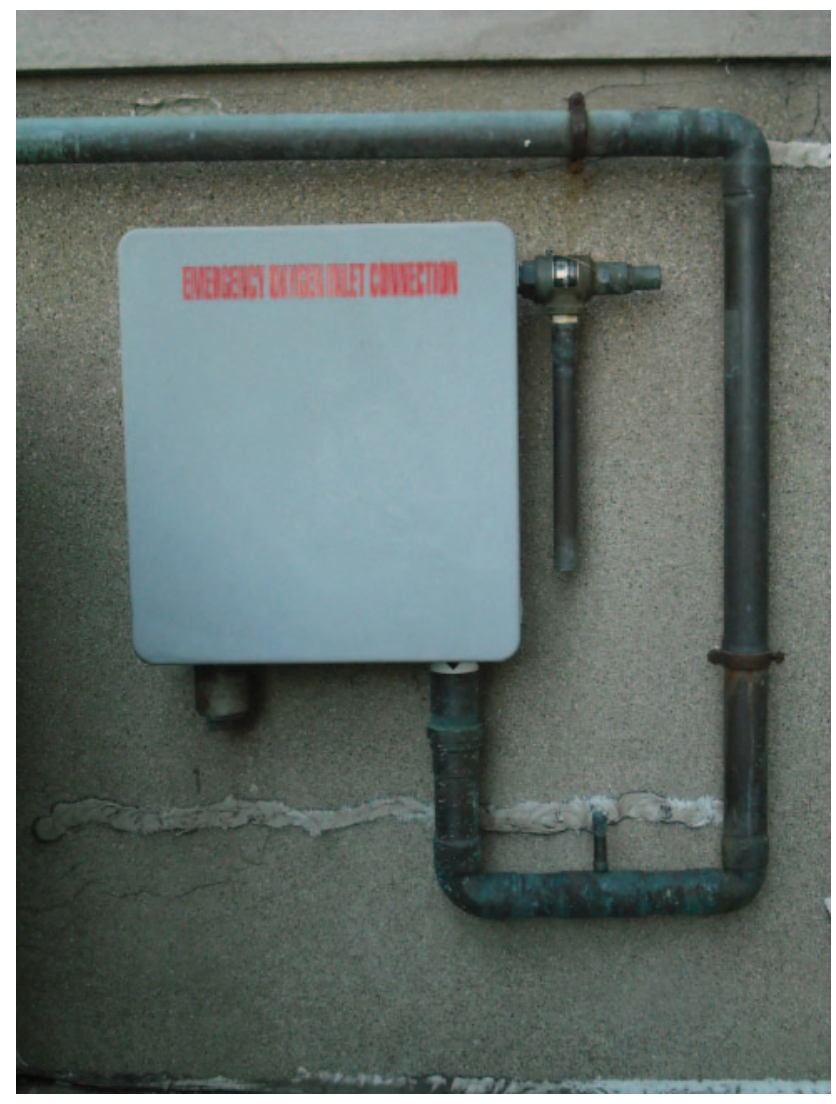

Fig. 3. University Hospital emergency oxygen inlet.

1,330 gallons $(4,300,000$ gaseous $\mathrm{L})$. The average daily usage is approximately 300 gallons/d (977,000 gaseous L). After allowing for off-gassing, when full, the main storage tanks contain approximately 17 days of reserve at the current daily usage and the reserve tank supplies an additional 2 days. In the event of a disaster, even if the oxygen usage doubled, there would still be approximately 9 days of available oxygen from the LOX system.

\section{Vulnerabilities}

In the event the LOX system needed filling but the path to the LOX storage is blocked by wreckage, what are the other options? Many hospitals have lines leading to the outside of the facility at a different location from the LOX system and easily accessible from the street, in order to perform an emergency back-fill (Fig. 3). An oxygen tanker truck can attach to these lines and provide gaseous oxygen to the entire system until the LOX is refilled. In a survey of 35 Ohio hospitals, Stoller et al reported that only $63 \%$ of the hospitals had an external connector for emergency back-fill of the facility's oxygen system..$^{10}$ They also demonstrated that hospitals with a reserve liquid supply frequently used the same delivery piping as the main system. In this instance, if the delivery pipe is damaged by con- struction, the reserve tank is of no value. The absence of such a system negates one of the 2 backup plans, leaving only cylinders to supply the entire facility.

What if the emergency back-fill lines are inaccessible, the LOX system is damaged, or there is a break elsewhere in the facility's gas distribution system? This is similar to the scenario in the aftermath of the tornadoes that struck Mercy St Johns Hospital in Joplin, Missouri. ${ }^{11}$ In addition to the damaged LOX system discharging all the oxygen, and debris around the facility rendering the roads impassable, the emergency generator was destroyed, leaving ventilators without gas or electrical power other that the onboard backup batteries. Several critically ill patients died as a result. The final reserve oxygen supplies in a hospital are in high pressure cylinders. Our facility stockpiles H cylinders as the main cylinder backup, and also E cylinders that are normally used for patient transport but can be utilized in an emergency situation. Due to the E cylinder's relatively low volume of oxygen, it should be used for patients requiring low oxygen concentrations. A ventilator can exhaust an E cylinder in as little as 30 min, depending on the settings and operating characteristics, and ventilating with a manual resuscitator at $10 \mathrm{~L} / \mathrm{min}$ can last approximately $60 \mathrm{~min}$.

In order to back-fill the entire system with enough oxygen to supply our facility for 24 hours, it would require approximately $142 \mathrm{H}$ cylinders. Our facility has the ability to store about $10 \%$ of what would be needed for 24 hours of oxygen usage. The National Fire Protection Association has safety regulations on how pressurized oxygen must be stored, and it depends on the volume of gas contained in all the cylinders combined ${ }^{12}$ :

- $\geq 3,000$ cubic feet of oxygen requires lockable doors, storage racks or chains, indirect heat (if required), and dedicated ventilation.

- $>300$ cubic feet to $<3,000$ cubic feet of oxygen requires lockable doors and passive ventilation.

- < 300 cubic feet of oxygen (12-13 standard E cylinders) may be stored without any restrictions as an operational supply to support clinical operations.

The space needed and the regulatory requirements to store substantial quantities of cylinders are cost prohibitive to most hospitals, so a minimal number are kept on hand to provide oxygen reserves for a short time. Even if the facility had that many stored $\mathrm{H}$ cylinders, the manpower and coordination to accomplish this feat would be daunting at best. In order to better manage resources, hospitals generally will use $\mathrm{H}$ cylinders to back-fill the ICUs and areas of high usage first. Zone valves must be utilized to isolate these areas to ensure proper back-filling. The common practice is to place $\mathrm{H}$ cylinders throughout the ICU and attach them to the oxygen system via the available 
quick connects used to connect oxygen delivery devices to the distribution lines. The number of $\mathrm{H}$ cylinders required depends on the number of beds and ventilators and high flow devices in use. This technique is fraught with problems. Hospital regulations require that these high pressure cylinders not be placed in the same room as patients. If the ICU is full, which is often the case, patients must be moved to other areas or placed in rooms with other patients to make rooms available to allow back-filling. Depending on the size of the ICU and number of high flow devices in use, several rooms must be vacated to ensure there is adequate pressure in the lines so the devices operate correctly. There is often a substantial pressure drop the farther away a high use device is from the closest cylinder. Part of the problem is the lines available at the bedside are too small to provide the needed flow to these devices. The number of rooms available to place cylinders, size of the zone to be back-filled, amount of gas needed, and number of cylinders and manpower available to monitor and change them compound the problem of using this technique.

The maintenance department in our facility has tested another method that alleviates many of these problems. If the gauge is removed at the zone valve and the cylinder is attached there, the system is back-filled, allowing a smaller pressure drop with more pressure and flow available, due to larger diameter pipes at the zone valve. $\mathrm{H}$ cylinders can be banked together to provide an adequate volume of oxygen to supply the needs of the zone. Additionally, zone valves are away from the patient care areas, eliminating patient movement to free up rooms. Ideally, to conserve oxygen in the ICU, ventilators would have internal compressors to power the devices and bleed in low flow oxygen to obtain the desired oxygenation. Many hospitals do not have internal compressors on the ICU ventilators, due to the purchase and maintenance costs. Alternatively, many transport ventilators have internal drive systems and could be used in place of some ICU ventilators if oxygen conservation is required, although hospitals generally have many more ICU than transport ventilators. Careful patient selection must be considered when deciding whom to place on the transport ventilator.

Patients on the wards requiring a few liters of oxygen can be managed on the smaller E or D cylinders. An E cylinder can supply oxygen to a patient requiring $2 \mathrm{~L} /$ min for approximately 5.5 hours, assuming the cylinder is full. The actual number of liters in a cylinder is subject to the specifications of individual manufacturers and filling practices of the provider, but further discussion of this issue is beyond the scope of this paper. Cylinder pressures must be closely monitored to ensure that patients have adequate oxygen supplies when using cylinders as the primary oxygen source.
What if only a portion of the oxygen distribution piping system is damaged? This could happen as a result of a construction or maintenance mishap, an act of terrorism, an air or ground vehicle accident, or any other event that affects only a portion of the facility. Let us say our helicopter malfunctioned and crashed into the side of the facility, affecting the third and fourth, east wing floors and breaking the oxygen risers (vertical pipes). Oxygen ceases to be transported to the 5 floors above the affected area on that side of the building. The appropriate response would be much like the scenario of a damaged LOX system. The zone valves would be closed before and after the affected area, and the floors above would be back-filled with $\mathrm{H}$ cylinders if the ICU is affected or E cylinders if wards are affected, or both. Simultaneously, the patients on the floors where the accident occurred would be assessed for medical treatment and evacuated to another part of the building. Although an accident such as this does affect the entire building or oxygen system, the direct involvement of patients, along with ensuring the unaffected patients' oxygen needs are met and uncontrolled discharging oxygen is not increasing the risk of fire, clearly requires as many resources as does a LOX malfunction. Hospitals must include as many scenarios as possible when designing a disaster plan to include oxygen utilization. The amount of planning and coordination between departments when performing a scheduled oxygen shutdown is extensive. No less preparation should take place when planning for the unlikely event of a disaster.

\section{The Community}

\section{Vulnerabilities}

In the wake of a disaster or mass casualty event, those affected in the community may seek medical treatment and assistance, which can quickly overwhelm hospital emergency departments. What are the vulnerable groups that inundate the emergency department following a disaster?

- Those dependent on home healthcare and assistance

- Those with chronic diseases

- Those dependent on power supplies such as oxygen concentrators, ventilators, suction, wheelchairs, and refrigerant dependent medications ${ }^{13}$

The latter 2 groups pose the greatest risk to outstripping the capabilities of emergency departments. Those patients receiving home oxygen and/or mechanical ventilation will be immediately affected with the loss of power, due to the use of an electrically powered ventilator and/or a concentrator as their oxygen source. Many home ventilated patients do not require oxygen, and those who do have low 
requirements that can be bled in via a low flow device such as a concentrator. Home care providers typically provide $\mathrm{H}$ or $\mathrm{E}$ cylinders or LOX as a backup in case of power loss. For a patient requiring $2 \mathrm{~L} / \mathrm{min}$ continuously, an $\mathrm{H}$ cylinder will last nearly 2.5 days, whereas an E cylinder will only last 5.5 hours. If travel is possible, patients with limited oxygen reserves will go to the hospital emergency departments to seek help. Often all that is needed is electricity to which to plug their concentrator, but generally they do not bring their concentrator with them when presenting to the emergency department. This further stresses the already overwhelmed emergency departments, which are trying to treat wounded and acutely ill patients but must allocate additional resources to find oxygen outlets for these patients. If patients have their own concentrator, they can be placed in areas where there is no piped-in oxygen but electricity is available, freeing manpower and oxygen resources for those in acute need.

\section{Effect on Hospitals}

After a large disaster, when the flow of patients into the emergency department, and eventually into the in-patient population, continues to increase, discharging those inpatients and redirecting those presenting to the emergency department who are the least ill becomes necessary. Often these are the patients in need of medication, oxygen, or electricity to power a medical device. Transferring patients to other hospitals after a disaster is highly unlikely, since they will most likely be experiencing the same surge capacity problems, so alternative locations to send patients must be explored.

Clearly the way to prevent the surge of people into emergency departments would be to enable these same people to stay in their own homes if power failure were the main problem. There are critics who would say the obvious solution for someone who has an electrically powered medical device such as a ventilator or oxygen concentrator is to have an emergency generator available in the event of a power outage. The issues surrounding this solution are purely economic. Many people who require these lifesaving medical devices are in the lower income brackets and do not have the means to purchase a generator, plus the dramatic price increase of fuel to power a generator compounds the problem for those on a fixed income. Another solution would be for government assistance to pay for generators for these patients to use as a backup. Again, cost is the limiting factor. The exact number of home oxygen recipients is unknown. As a reference, Medicare provides home oxygen to over one million beneficiaries ${ }^{14}$ at a cost of $\$ 2.15$ billion. Of the Medicare patients, $94 \%$ of the oxygen is provided by concentrators, $4 \%$ by LOX, and the remainder by cylinders. ${ }^{15}$ With recent government spending reductions at every level, including Medicare and durable medical equipment reimbursement, adding additional millions of dollars to purchase generators is not an option, especially with the large cuts in oxygen reimbursement in the past decade. Private insurance companies most often use the Medicare reimbursement rate, so it is assumed that a high percentage of their patients are receiving oxygen via concentrator as well.

\section{Home Oxygen Patients Disaster Planning}

So how does help reach these people in need, usually in rural areas with limited resources, with loss of electricity to power their concentrator and/or ventilator? There are resources available in the community, but the patients need to know how to access them. In the state of Florida, home health providers encourage patients to have a personal plan in case of an emergency. FEMA has an entire Web site devoted to preparedness, which has an abundance of information to help citizens prepare for an emergency, including a downloadable form that families can fill out to develop their personal plan. FEMA has recently added text messaging features in order for people to request and receive information (http://www.ready.gov). State and local governments also have Web sites dedicated to disaster preparedness, but they require the people who need the services to initiate the process by downloading and filling out forms.

What about those people who do not have cell phones or do not know how to text or use computers to access the available information? Utility companies in every state operate "medical priority lists," allowing people with special needs, medical or otherwise, to complete a form letting the company know their needs in an emergency so that they can receive preferential ${ }^{14}$ repair service when the services are interrupted for an extended period. Two questions come to mind. How do people learn about this service, and is there a guarantee these patients will have their services restored first if tens of thousands of homes are without utilities? The answer to both questions is unknown. An Associated Press survey found that these programs vary state to state and that only a small percentage of patients know that the services exist. ${ }^{16}$

The point here is that, as far as we can determine, no formal plans exist to help these patients with medical needs, especially oxygen-much less to identify who they are. If no one knows who they are, how can they receive help? A few years ago, the city of Seattle, Washington, attempted to develop a database of people who would require special aid in the event of a disaster. Unfortunately, it was abandoned due to the Health Insurance Portability and Accountability Act of 1996 (HIPAA) privacy regulations. The ability to identify those in need of immediate help due to life threatening medical conditions is the first step toward developing a comprehensive plan for a disaster. Door 
to door searches, which typically occur days after the incident, often find people when it is too late to help them.

\section{Alternate Care Facilities}

If patients are unable to stay in the home following a disaster, what are other options? Formerly labeled "medical needs shelters" and "special needs shelters," alternate care facilities (ACFs) can fill the need for caring for stable patients. An ACF will provide care for those who have medical needs and cannot be cared for by the existing medical care facilities or in general shelters. An ACF is not a substitute for an acute care facility, but is capable of caring for patients requiring subacute and chronic health needs and monitoring of medications and vital signs. They are invaluable in relieving pressure on healthcare systems when demand is high. ${ }^{17}$ ACFs can be many different sizes and shapes, and operate in ways that accommodate those who present seeking help. They can be as simple as a medical aid station or as complex as the Houston Astrodome or the New Orleans Convention Center after Hurricane Katrina. ${ }^{18}$

There is a plethora of information available concerning ACFs. A Google internet search of "alternate care facility" yielded 540,000 sites and "special needs shelters" yielded another 75,000. Many of the Web sites were from cities and counties in the state of Florida detailing the services offered at their respective ACFs. Florida has an extensive network of these facilities and experience in dealing with disasters, due to the numerous hurricanes that have hit the state, but does not have a formalized plan of how to help patients on home oxygen, such as the database mentioned earlier. As with many other states, counties, and cities that offer disaster preparedness programs, each of the counties have downloadable ACF application forms, but, again, the process must be initiated by the patient. At least if patients fill out and return the form outlining their medical needs, if or when they present to the facility in an emergency, the goal is to have their needs met. If they are receiving oxygen at home and either exhaust their supply or have no electricity to power their concentrator, they will be able to get oxygen and/or electricity, as well as medications to manage their lung disease at the facility.

In times after a disaster, resources may be in short supply, so patients should be encouraged to bring their equipment with them when presenting to an ACF. Having their own concentrator, oxygen tubing, nebulizer, and compressor will help ensure supplies are available for others. The caveat to having patients bring their own concentrator is the weight and having the space in a vehicle to transport it. Patients on home oxygen are often debilitated, and a stationary concentrator can weigh 30 pounds or more. If the patients have no help, it may be unlikely they can lift the device to get it in a vehicle. Portable concentrators are much lighter, usually $<20$ pounds, allowing for greater mobility, although patients do not always have them and must use cylinders to travel. Having an organized plan for the home oxygen patient during a disaster would help the community be better prepared to care for them.

In a survey of Japanese home oxygen patients, the number one concern was disasters and electrical blackouts. Additionally, 2 of their most common demands were a wish for subsidizing electrical costs of operating a concentrator and an explanation of the response of home oxygen providers to a disaster. ${ }^{19}$ Kobayashi et al examined the effect of the Japanese earthquake and tsunami on home oxygen patients seen at the Japanese Red Cross Ishinomaki Hospital. ${ }^{20}$ Much like in the United States after a disaster, 83 home oxygen patients presented to the hospital in the 15 days following the incident, 70 within the first 3 days. Of the Japanese home oxygen patients, 94\% use concentrators. Due to power outages and blocked roads that prevented delivery of emergency cylinders, the oxygen-dependent patients had nowhere else to go but the hospital. The facility quickly ran out of flow meters and outlets to attach to the central oxygen piping system, so home care companies were contacted to provide concentrators. On day 3 following the incident a temporary shelter was established inside the hospital, and the stable oxygendependent patients were transferred there to receive oxygen. The focus was for these patients to receive their regular treatments for their lung disease and prevent exacerbations, which would put additional strain on the hospital and increase costs. Only $20 \%$ of these patients experienced exacerbation of their disease, which was considered acceptable under the circumstances. Hospital officials concluded that patients receiving home oxygen should present to the hospital following a disaster, due to their need for resources. They also stated that a community-based plan to care for these patients in emergency situations is warranted, much like what is needed in the United States. A PubMed and Google search for alternate care type facilities in Japan yielded no results, so we assume no such care site exists, rendering the hospital as the only choice for care following a disaster, even if all that is needed is oxygen or an electric supply to power a concentrator.

What are the oxygen sources available to the community and ACFs in the event of a disaster? Oxygen resources utilized out of the hospital setting must be able to be transported to the areas in which they are needed. Oxygen cylinders and concentrators are the most readily available in emergency situations, due to home care providers generally having at least a small supply on hand, and can be easily transported to ACFs. Stationary concentrators can produce up to $10 \mathrm{~L} / \mathrm{min}$ and could be used by several patients simultaneously, depending on their needs. Portable concentrators are limited to a maximum of $3 \mathrm{~L} / \mathrm{min}$ of 


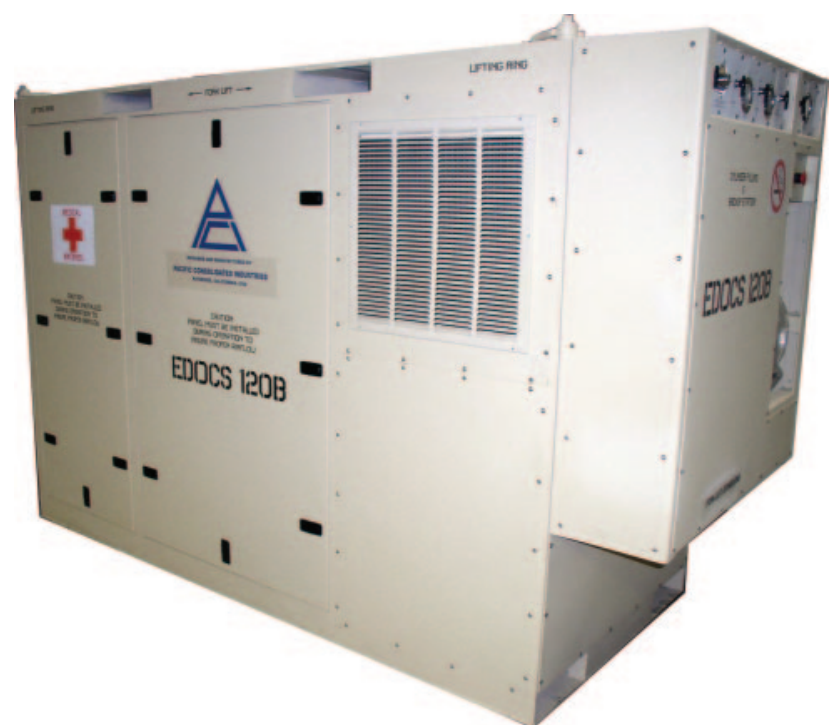

Fig. 4. Expeditionary Deployable Oxygen System (EDOCS). (Courtesy of $\mathrm{PCl}$.)

continuous flow, although pulse-dose technology can often maximize the oxygen output, but still can be used only by the single patient. Ideally, if a patient presents to an ACF, they have their own concentrator with them. These smaller, more mobile concentrators can initially be of help in a disaster situation until other forms of oxygen are made available that can administer oxygen to multiple people at once.

\section{Oxygen Sources}

\section{Concentrators}

Large commercial oxygen concentrators can produce much more oxygen than traditional home concentrators: some large enough to supply entire hospitals. Innovative Gas Systems of Houston, Texas, manufactures oxygen generators that produce oxygen ranging from 100 cubic feet per hour, weighing $300 \mathrm{~kg}$, to over 3,000 cubic feet per hour, weighing 14,000 kg. Oxygen Generating Systems International of North Tonawanda, New York, manufactures a unit that produces 5,000 cubic feet per hour. The larger oxygen generators occupy as much or more physical space, and can cost as much as a LOX system. ${ }^{12}$ Clearly the size, weight, decreased mobility, and high cost exclude their use in the disaster environment. PCI of Riverside, California, manufactures concentrators that are meant to be used for disaster relief, hospital backup, and austere military environments. The Expeditionary Deployable Oxygen System (EDOCS) (Fig. 4) is of moderate size and weight $(1,600 \mathrm{~kg})$, can be moved by a forklift, and can produce $120 \mathrm{~L} / \mathrm{min}$ oxygen at $85 \mathrm{psi}$. When configured with a boost compressor, the EDOCS can generate pressures of 2,250 psi to fill cylinders to take to remote loca-

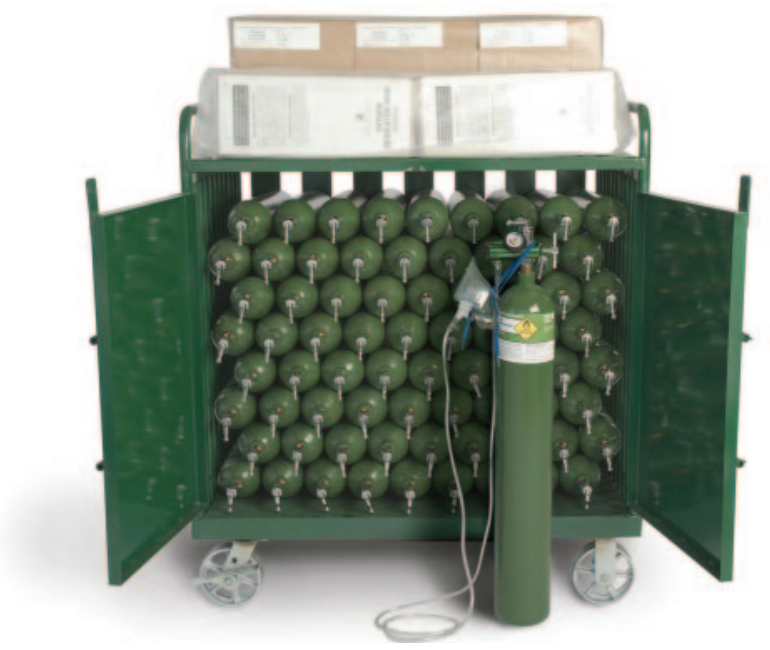

Fig. 5. National oxygen kit. (Courtesy of Airgas.)

tions. The portable oxygen generating system (POGS, On Site Gas Systems, Newington, Connecticut) manufactures a concentrator system that, like the EDOCS, can fill cylinders as well as provide $33 \mathrm{~L} / \mathrm{min}$ of oxygen, and is man portable. Many larger oxygen generating systems can be trailer-mounted for transport to alternate care sites during mass casualty/disaster events, but, due to their size, are not the first choice for an oxygen source.

\section{Cylinders}

Compressed gas cylinders are another option for oxygen supplies in a disaster situation. Most hospitals, home care companies, and oxygen providers stockpile cylinders as a backup in the event of an emergency. The limiting factors to storage of cylinders are physical space, the National Fire Protection Association regulations previously outlined, and physical handling requirements. Large $\mathrm{H}$ cylinders are heavy and require considerable space, since they typically are stored upright. Figure 5 shows an oxygen cylinder stockpiling system using E cylinders. This system stores 81 cylinders and can be convenient and space-conserving, but exceeds the 3,000 cubic foot threshold, and is subject to additional storage requirements. These requirements, coupled with the manpower necessary to move and change cylinders when empty, render this means of oxygen delivery appropriate only for a short time, especially if there are many patients requiring oxygen.

\section{Liquid Oxygen}

LOX remains the best method for storing large volumes of oxygen with a relatively small footprint. In a disaster scenario a single patient LOX does not offer any advantage over a personal concentrator or cylinder, but large mobile LOX systems offer advantages to many patients at 


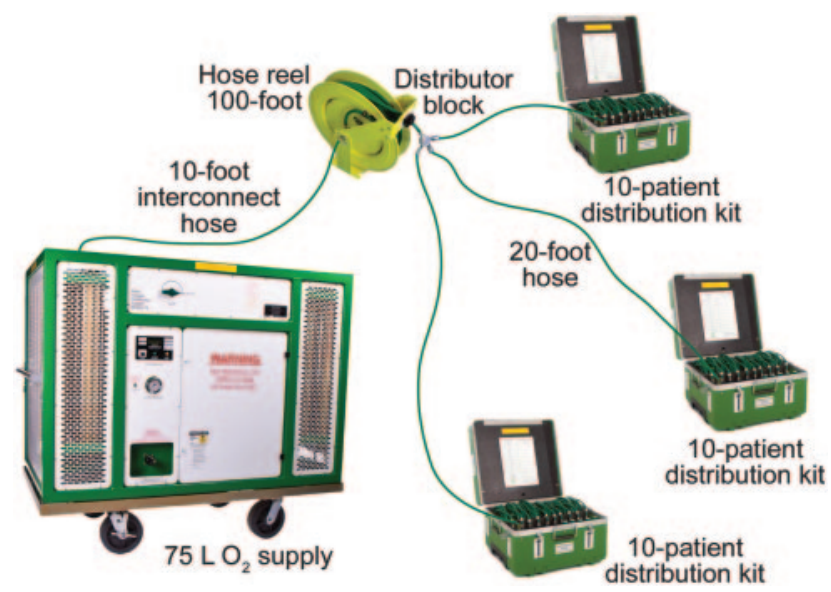

Fig. 6. Mass oxygen distribution system (MODS). (Courtesy of Essex Industries.)

once. These systems are wheeled or trailer mounted and can be transported to ACFs and supply oxygen to multiple patients. Figure 6 shows the mobile oxygen distribution system (MODS, Essex Cryogenics, St Louis, Missouri), which contains $75 \mathrm{~L}$ of LOX and can be connected to multiple 10-patient distribution kits. ${ }^{12}$ With over 64,000 gaseous liters of oxygen available, this system could supply $2 \mathrm{~L} / \mathrm{min}$ of oxygen to 30 patients for over 17 hours, although flow rates can be individually set for each patient if needed. Refilling the MODS via larger semi-trailermounted LOX systems could be a potential problem if roads are impassable and delivery is disrupted due to debris, but the capacity of the system allows time for rescue crews to clear roadways to facilitate deliveries.

\section{Multi-Patient Manifold Systems}

Oxygen delivery systems such as concentrators, cylinders, and LOX systems capable of generating high liters of gas flow have the potential to administer oxygen to several patients at once. As outlined above, the MODS is an integrated system of LOX and patient distribution kits intended for this purpose. Other systems and manifolds are available to enable multi-patient use of these systems. Some are available as kits that include hoses, nipple adapters, gauges, tubing, masks, cannulas, etc (Fig. 7). Others provide manifolds that allow multiple patient tubing attachments without the other accessories. The preferred manifolds allow for individual flow adjustment for each patient (Fig. 8). Many of these manifolds can be attached together in a series, to provide greater flexibility in administering oxygen to many patients, which would be ideal for use with high capacity oxygen delivery systems.

\section{Summary}

Planning for oxygen reserves and attempting to anticipate oxygen use during a disaster or mass casualty event in

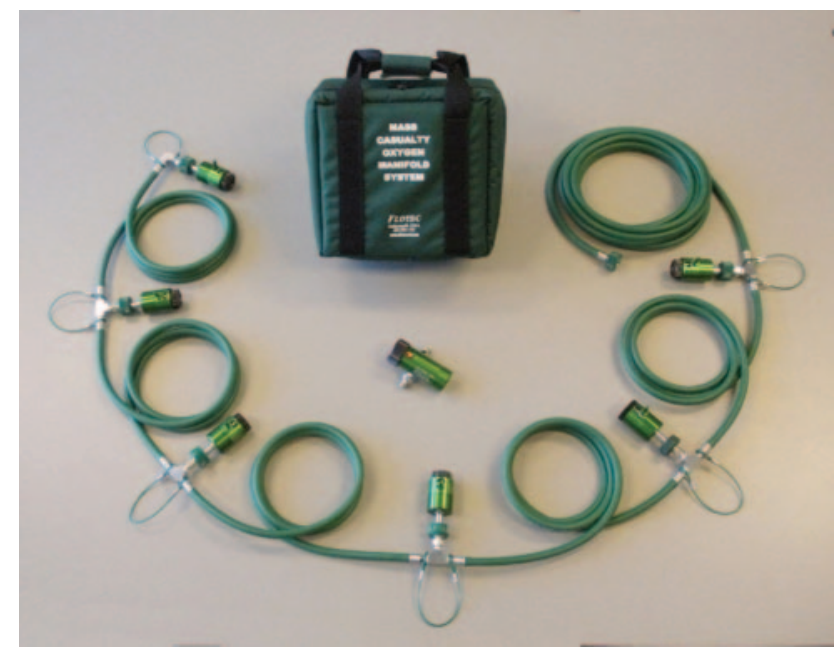

Fig. 7. Mass casualty oxygen manifold system. (Courtesy of Flotec.)

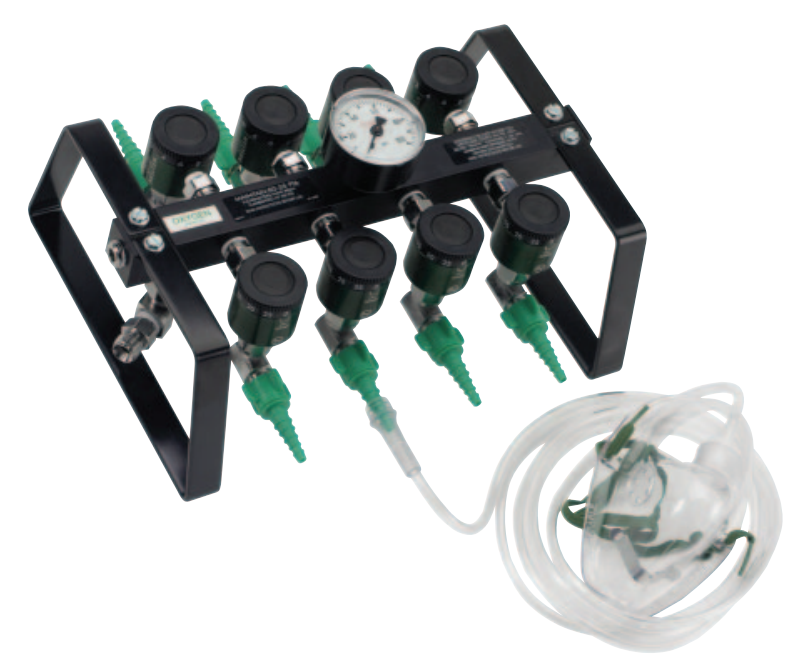

Fig. 8. OCTI-FLO ${ }_{2}$ emergency oxygen manifold. (Courtesy of Western Medica.)

either the hospital or alternate care setting is not a simple task. All variables cannot be accounted for in every situation. Due to Joint Commission requirements, hospitals have developed contingency plans for disasters/mass casualty events, and have periodic drills to assess these plans. Typically these plans focus on the organization's ability to manage the patient surge and management of manpower and hospital resources. Hospitals have backup oxygen supplies, usually in the form of compressed gas cylinders, in the event of main oxygen system failure. Due to cost and regulations for large volumes of cylinder storage, backup oxygen supplies appear to be inadequate if primary system failure is prolonged. Hospitals typically utilize "just in time" suppliers of oxygen and other supplies, which generally offer prompt delivery. In a disaster situation this service may be hampered or unavailable, putting the hospital backup oxygen supply at risk of depletion. A smaller, 


\section{Oxygen Supplies in Disaster Management}

backup LOX tank often serves as a reserve, but it is often attached to the same line as used by the primary system, rendering it useless if the main line is damaged. As an additional backup, hospitals often have emergency backfill lines that can be used to attach to a bulk oxygen tanker, provided they are accessible following a disaster affecting the hospital.

$\mathrm{ACFs}$ have proven to be invaluable in relieving pressure from the mass influx of patients into hospitals following a disaster. Planning for oxygen requirements for these facilities can be difficult and logistically challenging. Stable patients receiving home oxygen will often present or be transferred to these facilities due to power outages rendering their concentrators inoperable. The community must have a plan on how and what source of oxygen to have available. Often federal assistance will become available, but the community must be able to care for these patients for at least the first 24-48 hours. LOX is the most efficient system for providing oxygen to many patients at once in these facilities, due to the small footprint for the same volume of gas, as compared to cylinders and large concentrators. As with hospital backup oxygen supplies, refilling of the LOX system may be hampered by debris following a disaster. Communities need to develop a plan on ways to inform the electrically dependent, home oxygen patient about utility companies' medical priority lists, so that they will be among the first to have their electrical service restored after an outage. When all that may be needed is electricity to operate an oxygen concentrator, this may allow them to remain at home and not place additional stress on the medical system that must also care for critically ill and injured patients.

\section{REFERENCES}

1. Centre for Research on the Epidemiology of Diseasters (CRED). EM-DAT: the International Disaster Database. http://www.emdat.be/. Accessed October 25, 2012.

2. Benjamin E, Bassily-Marcus AM, Babu E, Silver L, Marin ML. Principles and practice of disaster relief: lessons from Haiti. Mt Sinai J Med 2011;78(3):306-318.

3. US Department of Homeland Security. Preparedness, response and recovery publications. http://www.dhs.gov/preparedness-responseand-recovery-publications. Accessed October 25, 2012.

4. Christian MD, Devereaux AV, Dichter JR, Geiling JA, Rubinson L. Definitive care for the critically ill during a disaster: current capabilities and limitations: from a Task Force for Mass Critical Care Summit Meeting, January 26-27, 2007, Chicago, IL. Chest 2008; 133(5 Suppl):8S-17S.

5. Daugherty EL, Branson R, Rubinson L. Mass casualty respiratory failure. Curr Opin Crit Care 2007;13(1):51-56.
6. Chaljub G, Kramer LA, Johnson RF III, Johnson RF Jr, Singh H, Crow WN. Projectile cylinder accidents resulting form the presence of ferromagnetic nitrous oxide or oxygen tanks in the MR suite. AJR Am J Roentgenol 2001;177(1):27-30.

7. Patel R. RUH's intensive care unit catches fire. November 23, 2011. http://topnews.us/content/244865-ruh-s-intensive-care-unit-catchesfire. Accessed October 25, 2012.

8. Guenther R, Vernon W. Global lessons in healthcare. October 1, 2010. http://www.healthcaredesignmagazine.com/article/globallessons-healthcare. Accessed October 25, 2012.

9. Centers for Disease Control and Prevention Office of Public Health Preparedness and Response. Strategic National Stockpile (SNS). http://www.cdc.gov/phpr/stockpile/stockpile.htm. Accessed October 25,2012

10. Stoller JK. Stefanak M, Orens D. Burkhart J. The hospital oxygen supply: an "O2K" problem. Respir Care 2000;45(3):300-305.

11. Manley D, Bollin S, Dodson R, Fovargue R, Denton B. Medical response to Joplin tornado May 22, 2011. August 2, 2011. http:// doh.sd.gov/Prepare/Hospital/Documents/Joplin.pdf. Accessed October 25, 2012.

12. Ritz RH, Previtera J. Oxygen supplies during a mass casualty situation. Respir Care 2008;53(2):215-225.

13. Aitken P, Leggat P. Considerations in mass casualty and disaster management. http://cdn.intechopen.com/pdfs/31947/InTechConsiderations_in_mass_casualty_and_disaster_management.pdf. Accessed October 25, 2012.

14. Hoban N, Braithwaite S, Kasowitz L, Norris K, Glaudemans J; for the Council for Quality Respiratory Care (CQRC). Home oxygen therapy: an analysis of recent Medicare payment policy. December 2008. http://ex.democracydata.com/CQRC/Advocacy/avalere_2008. pdf. Accessed October 25, 2012.

15. United States Government Accountability Office. Report to Congressional requesters. Medicare home oxygen: refining payment methodology has potential to lower program and beneficiary spending. January 2011. http://www.gao.gov/assets/320/315094.pdf. Accessed October 25, 2012.

16. Associated Press. Keeping home life-support up during outages. http:// www.msnbc.msn.com/id/28619557\#.T41v0NlyVip. Updated January 12, 2009. Accessed October 25, 2012.

17. Cantrill SV, Pons PT, Bonnett CJ, Eisert S, Moore S. Disaster alternate care facilities: selection and operation. AHRQ Publication no. 09-0062. Rockville, MD: Agency for Healthcare Research and Quality; October 2009. http://archive.ahrq.gov/prep/acfselection/ dacfreport.pdf. Accessed October 25, 2012.

18. Institute of Medicine Forum on Medical and Public Health Preparedness for Catastrophic Events. Establishing alternate care facilities. http://www.ncbi.nlm.nih.gov/books/NBK32863/. Accessed October 25, 2012.

19. The Japanese Respiratory Society. Japanese white paper on home respiratory care (summary). Presidential Symposium Report, the 45th Japan Respiratory Society Annual Conference. http://www.jrs.or.jp/ quicklink/glsm/guideline/nopass_pdf/home_care_e.pdf. Accessed October 25, 2012.

20. Kobayashi S, Hanagama M, Yamanda S, Yanai M. Home oxygen therapy during natural disasters: lessons from the great East Japan earthquake. Eur Respir J 2012;39(4):1047-1048.

\section{Discussion}

McCoy: Hospitals are wasting a lot of gas and seem to think it doesn't matter because oxygen is inexpensive, but it does matter. We can use the gas more efficiently and therapeutically. You pointed out that some hospitals are 100 years old, but so are the regulations. It's time for the regulatory agencies to start looking into more practical and realistic guidelines so that we can adapt to that environment. In the hospital I know we could be more efficient. Related to disaster pre 
paredness, one of the first things I tell a COPD patient is to stay calm. Some patients panic, yet many of them can turn off their $\mathrm{O}_{2}$ if they're calm. If they know what to do and they have a plan and stay calm, they can do well. The technology is mostly electric now, and that is an issue. After a disaster the home-care provider brings in tanks and liquid $\mathrm{O}_{2}$ systems because the concentrators don't work. That is difficult to address when we don't much use tanks and liquid any more. What we should offer patients is education and a plan that guides them through what to do when a disaster happens. That should be part of the education when the patient is set up with the $\mathrm{O}_{2}$ equipment, especially if they're in a danger zone.

Branson: I think Florida has done a pretty reasonable job, and part of that is because the director of emergency services at the state hospital association is John Wilgis, who's a respiratory therapist and used to be the president of the Florida society. He's done a lot, and they have developed ACFs. They have a lot of elderly patients on $\mathrm{O}_{2}$ in Florida, compared to a lot of other places, but these ACFs and special needs shelters will continue to be developed by FEMA. In the neonatal ICUs the nurses and therapists often keep the flow meters on non-stop so they can bag right away. That's a place to save oxygen. Anesthesia uses a lot of $\mathrm{O}_{2}$ because they run low flow continuously at night, so carbon monoxide doesn't build up in the $\mathrm{CO}_{2}$ absorbers. So there are lots of places you can improve efficiency in the hospital when you know you're going to have a shortage of gas.

Lewarski:* Disaster preparedness and managing home oxygen patients is a serious challenge. The home care companies, as part of the accreditation process, need to have a disaster plan. In the

\footnotetext{
* Joseph S Lewarski RRT FAARC, Invacare, Elyria, Ohio.
}

United States about $95 \%$ of the home $\mathrm{O}_{2}$ (at least the stationary component) is supplied by electronic concentrators.

I agree with your comments about the patient's reaction. In my experience, the first thing many patients do is head to the hospital. I was operating a home care company when we had the big blackouts in the summer of 2003. At that time we serviced about 1,500 home $\mathrm{O}_{2}$ patients and 60 home ventilator patients, and the majority were affected by the power outage, some for as long as 2 weeks. Many of the $\mathrm{O}_{2}$ patients went to the hospital right away and, unfortunately, the facilities did not have any cylinders to dispense, nor could they admit those patients. The hospitals contacted us and we coordinated cylinder deliveries to the facility, where they dispensed them to our patients. We had a disaster plan, but it's really untested until you are in the middle of a real event.

I've talked to companies who managed through 9/11, Hurricane Katrina, and other disasters, and they say that you're reacting to the moment. We were fortunate in our blackout in that many of the areas surrounding us had some power, and our cylinder supplier had power, so we got our empty cylinders refilled quickly. We also managed to get some ventilator-dependent folks to hotels with access to power, and replaced backup batteries on a regular basis. A lot depends on the size and severity of the disaster. If the disaster centers can provide power and the patients are educated to take their equipment with them, the problem is not quite as bad, but a 45 -pound concentrator may be a lot for somebody to grab when they're trying to get out of their house in a disaster.

Patient education is necessary, but also I think this entire area of disaster management in health care is in need of improvement. Home care is very fragmented, as you know, and the rules and regulations around disaster preparedness are being revised and improved.

There is some upside on electricity demand; many of the devices out to- day-particularly the portable devices-have very little electrical demand. Some of them are 60 Watts. Even the stationary concentrators that can produce $5 \mathrm{~L}-$ most of them operate at around 350 Watts. So, in comparison to the era gone by, they are much more efficient and the electrical demand isn't quite as bad. Almost all portable concentrators on the market today can operate on alternating current or lithium ion battery packs. I also think that pulse-dosing and intermittent-flow devices have an important role, even with patients who aren't currently using them. If you have cylinders, you can employ conservers. For at least the short-term for these patients, some $\mathrm{O}_{2}$ is better than none in those circumstances. There are still a lot of gaps.

McCoy: There's a good opportunity with the trend of economic constraints modifying the mix of oxygen products in home care, with a very large installed base of unused cylinders and liquid $\mathrm{O}_{2}$ equipment. Whoever is coordinating a disaster plan could find where all those resources are and put them into disaster preparedness. There's a large supply of unused inventory that could be accessed very quickly and filled up quickly in a disaster.

Lewarski: That's true. A lot of companies have thousands of cylinders in circulation within their systems. Despite all the new technology, cylinders are still the primary ambulatory $\mathrm{O}_{2}$ system in the United States. In a disaster-and we learned this after 9/11 and Hurricane Katrina-HME [home medical equipment] companies don't get any special consideration for being on the road. When only emergency vehicles can be on the road, the HMEs are also restricted. HMEs don't have special permission or sirens or any emergency travel assistance. An HME can be stuck in its location. It was difficult to access the patients or the facilities, because many of the companies couldn't drive where they needed to go. 